\title{
Temporal trend and spatial analysis of the HIV epidemic in young men who have sex with men in the second largest Brazilian Amazonian province
}

\author{
Iaron Leal Seabra ${ }^{1}$, Andrey Oeiras Pedroso ${ }^{1}$, Taymara Barbosa Rodrigues ${ }^{1}$, \\ Glenda Roberta Oliveira Naiff Ferreira' ${ }^{1}$ Ana Lucia da Silva Ferreira², Ricardo Alexandre Arcêncio³, \\ Dulce Gomes ${ }^{4}$, Richardson Augusto Rosendo da Silva ${ }^{5}$ and Eliã Pinheiro Botelho ${ }^{1^{*}}$
}

\begin{abstract}
Background: After 40 years of its starting, the HIV epidemic in Brazilian Amazon region remains on an increasing trend. The young men who have sex with men (MSM) have been the most impacted by the HIV in the last decade. However, much more than attributing the risk behavior to HIV uniquely to the individual, behaviors are shaped by social determinants of health (SDH). Despite the problem, there is a scarcity of studies evaluating the impact of SDH on HIV among young MSM and none of them were done in the Northern of Brazil. Therefore, the main goal of this study was to analyse the HIV epidemic among Brazilian Amazonian young MSM using temporal trends and spatial analysis.

Methods: We conducted an ecological study using reported cases of HIV/AIDS in young MSM living in Pará, the second larger Brazilian Amazonian province, between 2007 and 2018. Data were obtained from the Information System for Notifiable Diseases. For the temporal analysis, we employed a Seasonal and Trend decomposition using Loess Forecasting model (STLF), which is a hybrid time-series forecast model, that combines the Autoregressive-Integrated Moving Average (ARIMA) forecasting model with the Seasonal-Trend by Loess (STL) decomposition method. For the spatial analysis, Moran's spatial autocorrelation, spatial scan, and spatial regression techniques were used.

Results: A total of 2192 notifications were included in the study. Greater variabilities in HIV/AIDS population-level diagnosis rates were found in the festive months. The HIV/AIDS population-level diagnosis rates exhibited an upward trend from 2013 and this trend is forecasted to continue until 2022. Belém, the capital of Pará, presented the highest spatial risk for HIV/AIDS and was the only city to present spatiotemporal risk from 2014 to 2018. The geographic variation of the HIV epidemic was associated with the number of men with formal jobs, the average salary of men, and the percentage of people over 18 years old with elementary education.
\end{abstract}

\footnotetext{
*Correspondence: elipinbt@gmail.com

1 Universidade Federal do Pará, Programa de Pós-Graduação

em Enfermagem, Rua Augusto Correia, 01 - Setor saúde,

GuamáBelém 66075-110, Pará, Brasil

Full list of author information is available at the end of the article
}

(c) The Author(s) 2022. Open Access This article is licensed under a Creative Commons Attribution 4.0 International License, which permits use, sharing, adaptation, distribution and reproduction in any medium or format, as long as you give appropriate credit to the original author(s) and the source, provide a link to the Creative Commons licence, and indicate if changes were made. The images or other third party material in this article are included in the article's Creative Commons licence, unless indicated otherwise in a credit line to the material. If material is not included in the article's Creative Commons licence and your intended use is not permitted by statutory regulation or exceeds the permitted use, you will need to obtain permission directly from the copyright holder. To view a copy of this licence, visit http://creativecommons.org/licenses/by/4.0/. The Creative Commons Public Domain Dedication waiver (http://creativeco mmons.org/publicdomain/zero/1.0/) applies to the data made available in this article, unless otherwise stated in a credit line to the data. 
Conclusion: The upward trend of HIV/AIDS population-level diagnosis rate forecasted until 2022 and the variability of the epidemic promoted by the SDH brings an alert and subsidies to health authorities to implement more efficient and focalized public policies against HIV among young MSM in Pará.

Keywords: Social determinants of health, HIV, Youth, Spatiotemporal analysis

\section{Background}

In the last decade, young people have been highly impacted by the HIV epidemic. Approximately $30 \%$ of newly detected HIV cases worldwide are among young people [1]. In Brazil, the greatest increase in HIV detection rates occurs among young men, with most of them included in the men who have sex with men (MSM) group exposure category [2]. This group of young MSM is more likely to be infected with HIV than young heterosexual individuals. This phenomenon may be related to the earlier initiation of sex among young MSM, multiple sexual partners, social stigmatization as well as other social and behavioral factors that make them more vulnerable to HIV than young heterosexual men [3, 4]. According to the Brazilian Youth Statute, a person aged between 15 and 29 years is considered a young person [5]. Only in 2019, Brazil recorded 26,141 cases of HIV/AIDS among men with a predominance of cases in MSM exposure group compared to the heterosexual one (39.85\% vs. $39.5 \%$, respectively). However, in the Northern of Brazil the heterosexual group had a small predominance compared with the MSM group, from 2322 cases of HIV/ AIDS notified among men, about $45 \%$ were in MSM and about $48 \%$ in heterosexual men [2].

However, risk behaviors to HIV are shaped by social determinants of health (SDH) and cannot be attributed uniquely to the individual. SDH are the local conditions in which people live. They are comprised of cultural, social, and economic aspects which can lead to the occurrence of disease and risk factors [6]. Therefore, SDH confers a distinct identity on the HIV epidemic in each specific territory. In Brazil, factors associated with poverty, such as low income and low schooling, as well as the stigma against HIV and gays have been pointed as directedly associated with the HIV-positive status among young MSM $[7,8]$.

Among all Brazilian regions, the Brazilian Amazon is the poorest one with a large part of its population living in precarious conditions of housing and basic sanitation, low education level, low coverage of health services and low monthly wage [9]. These factors can explain the observed HIV epidemic scenery in this region, where in the last decade the HIV/AIDS detection rate increased by $24.4 \%$. Among the states that comprise the northern region, Pará had the second-highest increase in the HIV/AIDS detection rate (46.5\%). Among the Brazilian federative units and capitals, Pará and its' capital Belém, stood out as the fourth and second in HIV/AIDS detection rates rank, respectively [2].

Spatial and temporal analysis techniques are useful tools for providing an enhanced understanding of the HIV epidemic. Spatial analysis allows the visualization of regions with the highest epidemiological pressure and associates the phenomenon with SDH. In comparison, temporal analysis provides insight into the epidemic's behavior over time. It also provides an evaluation of the impact of implemented public policies designed to control the epidemic $[10,11]$.

Despite the identified problem, a literature review with the descriptors "HIV", "young," "men who have sex with men" and "spatial analysis" resulted in no studies. In addition, considering the impact of HIV in the young MSM and the epidemiological scenery in the Brazilian Amazon region, it is necessary to evaluate how the implemented public policies to fight HIV are impacting the young MSM and to comprehend the epidemic geographical variability promoted by the SDH to implement more focalized and efficient public policies against HIV in this province.

Therefore, we aimed to analyze the HIV epidemic among Brazilian Amazonian young MSM employing temporal trend and spatial analysis in Pará, Brazil. For the temporal analysis we employed the Seasonal and Trend decomposition using Loess Forecasting model (STLF) method For spatial analysis, we used Moran's spatial autocorrelation, spatial scan, and spatial regression.

\section{Methods}

\section{This was an ecological study}

Study design and population

Pará is in the northern region of Brazil and is the secondlargest state in terms of territorial area $(1,245,870,707$ $\mathrm{km}^{2}$ ). It is divided into 144 municipalities with a population of 8,690,745 inhabitants [12] (Fig. 1). Despite its abundance of natural resources, the state has the third-lowest Brazilian Human Development Index $(\mathrm{HDI}=0.698)$, high income inequality distribution $($ Gini $=0.53)$, and a low coverage rate of primary healthcare services $(59.13 \%)$. The majority of the primary healthcare places $(68.2 \%)$ are in urban areas. Thus, people living in rural population zones have difficulty accessing health services [13]. 


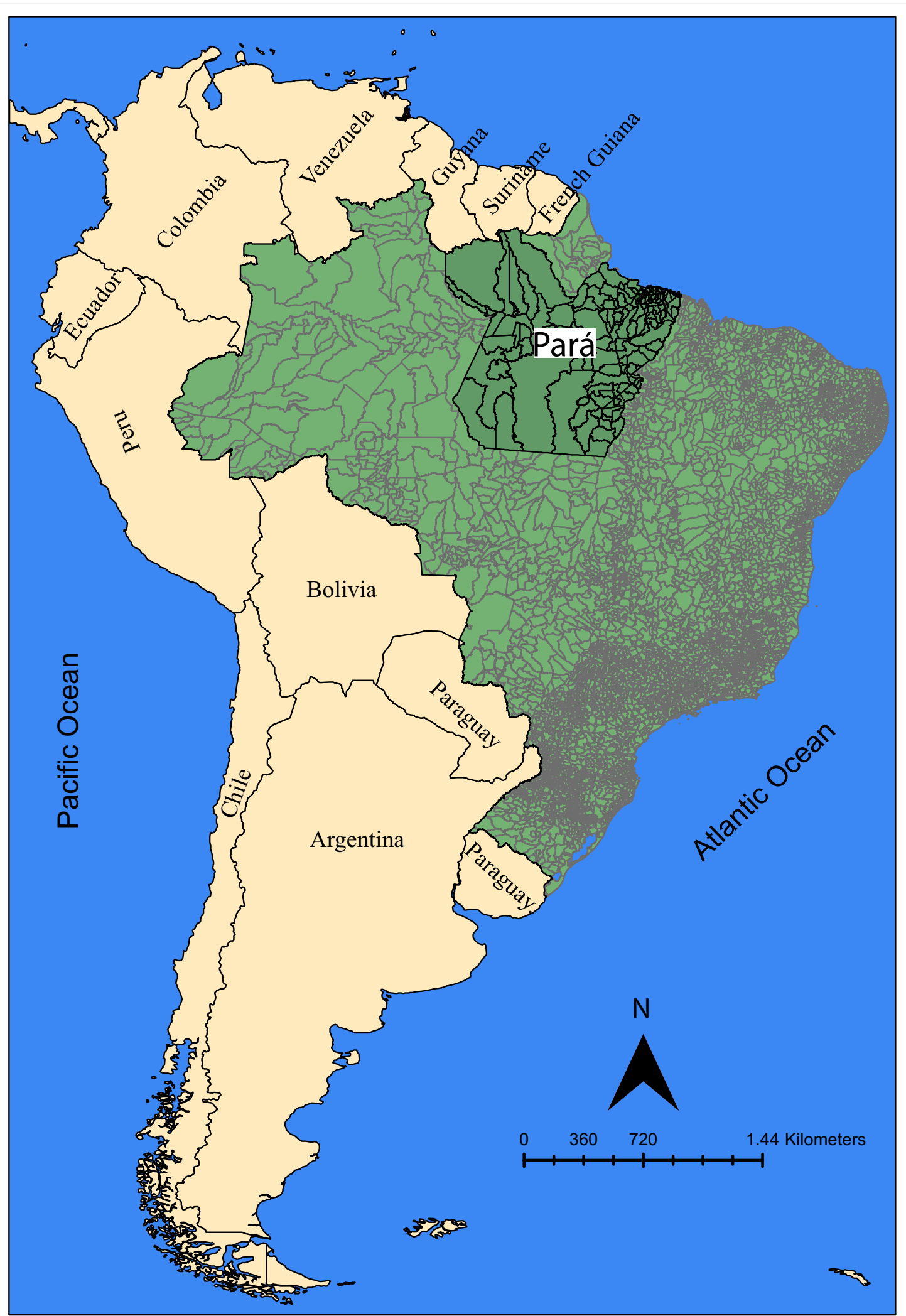

Fig. 1 Spatial location of Brazil (light green) in South America continent and of Pará 
The study population consisted of HIV/AIDS cases among young MSM living in Pará. These cases were recorded in the Information System for Notifiable Diseases between 2007 and 2018. All data were provided by the State Department of Public Health in Pará. Only notifications containing the city of residence and age of the individual were included in the study. The following variables were collected: age, year of diagnosis, race, educational level, and city of residence. Data were double-checked and redundant and inconsistent data were removed.

\section{Data analysis}

Descriptive analysis was performed using Microsoft Office Excel $365^{\circledR} 2019$ (Microsoft Corporation, Santa Rosa, CA, USA). The results were expressed as absolute values (n) and relative frequencies (\%).

For the temporal analysis, we used the monthly HIV/ AIDS population-level diagnosis rates following previous study [14]. To the calculus of the population-level diagnosis rates, the number of cases reported in a specific month in young MSM in Pará was divided by the population projection of all young men aged 15-29 in the specific year living in Pará due to the number of MSM are not available in Brazil. It was then multiplied by 100,000 inhabitants.

The temporal analysis was done employing a Seasonal and Trend decomposition using Loess Forecasting model (STLF), a hybrid time-series forecast model, which combines the Autoregressive-Integrated Moving Average (ARIMA) [15] forecasting model with the SeasonalTrend by Loess (STL) decomposition method [16]. The great advantage of this new approach is the high capacity to make accurate long-term forecasts, contrary to the isolated use of ARIMA models, whose long-term forecasts tend to the average of the series, therefore unrealistic.

The STL method is a filtering method that consists of decomposing a time series as a sum of three components of variation: seasonality, general trend and remainder. This decomposition is based on robust local regression, employing a locally weighted regression (Loess), of trend and seasonal components. On the other hand, the STLF method considers the decomposition of the series into three components and, from the three estimated components, uses this information to predict the future values of the series. To this end, it considers that the seasonality pattern remains the same in the coming years and takes together the trend and the error (usually called seasonally adjusted data). An ARIMA model is fitted to this combination and, based on this, the corresponding forecasts are made.

Before proceeding to the modelling of the series, and the consequent prediction of future values, possible structural changes in the series were investigated using the method developed by Zeileis et al. [17]. All analyses were performed on RStudio software (Version 1.4; RStudio, Boston, MA, USA) using the strucchange [17] and forecast [18] R packages.

In the spatial analysis, the spatial distribution and autocorrelation of the HIV/AIDS population-level diagnosis rates were determined using ArcGIS 10.1, software (ESRI, Redland, California, United States). The municipalities HIV/AIDS population-level diagnosis rates were calculated for quadrenniums (2007-2010, 2011-2014, and 2015-2018) and for the entire period of the study to avoid annual fluctuations. The calculation of the population-level diagnosis rates was based on the average population projections of young men in the municipalities for each specific period [14]. Spatial autocorrelation of the HIV epidemic among young MSM was analyzed using Moran's global index $(I)$ with 999 permutations. This was followed by the statistical method and local indicators of spatial association (LISA). A queen-type W contiguity matrix was employed in both analyses and neighboring municipalities were considered to share borders and nodes.

$I$ index ranges from -1 to 1 , where 1 indicates a direct correlation, 0 indicates randomness, and -1 indicates an inverse correlation. Four types of clusters can be identified in the LISA map: high-high and low-low indicates a direct correlation, whereas low-high and high-low indicates an inverse correlation.

Spatial scan analysis based on the discrete Poisson model was performed using the SatScan 9.7 software (Kulldorf, Cambridge, MA, USA) to assess the regions at risk for HIV/AIDS [19]. The following criteria were used for the spatial risk detection: non-overlapping clusters with a maximum size of $50 \%$ of the population at risk and 999 replications. The same criteria were used for the spatio-temporal risk detection, however considering the maximum size of the temporal cluster as equal to $50 \%$ of the study period. Each risk region had a relative risk (RR) and $95 \%$ CI. Regions with $\mathrm{RR} \geq 1$ and $p \leq 0.05$, were considered at risk. RStudio 1.4 software was used to calculate the $95 \% \mathrm{CI}$.

The geographic variability of the HIV/AIDS epidemic in Pará promoted by SDH was assessed using geographically weighted regression (GWR) analysis [20]. The HIV/ AIDS population-level diagnosis rate for the 12 years of the study was considered a dependent variable. The SDH were the independent variables.

The SDH projected for 2018, based on 2000 and 2010 census data, were obtained from websites of the Institute of Applied Economic Research and Brazilian Institute of Geography and Statistic. They were then categorized into the following dimensions: Education: (1) percentage of 
people aged 18 or over without complete primary education and with informal work, (2) elementary school dropout rate, (3) high school dropout rate, (4) percentage of people aged 18 or over with complete primary education, and (5) school attendance; Income: (1) people who live in households with per capita income less than the minimum wage and require more than an hour to arrive at work, (2) percentage of people between 15 and 24 years of age who do not study or work and have a per capita income equal to or less than the minimum wage, (3) proportion of people with per capita income less than or equal to half the minimum wage, (4) unemployment rate of the population of 18 years of age or over, (5) total number of families registered in the Bolsa Família Programme, (6) total number of families registered in Single Register of Social Programmes, (7) formal employment relationships-male, and (8) average salary of formal workers - male; Social prosperity: (1) municipal HDI (HDIm), HDIm-longevity, (3) HDIm-education, (4) HDIm-income, and (5) the social prosperity index; Primary Care Coverage: Environmental and Social Framework coverage.

For GWR, Pearson's correlation analysis was used to verify the correlation between the dependent and independent variables in RStudio. All correlations $(p \leq 0.05)$ were then analyzed through an ordinary least squares (OLS) regression model using the step-by-step method in MGWR software (ASU, MD, USA). The generated models were evaluated for multicollinearity and only those with variance inflation factor (VIF) values lower than 10 were accepted. The best explanatory model for this phenomenon was defined by the Akaike information criterion (AIC) value $(p<0.05)$. The OLS residuals were then analyzed for spatial autocorrelation to validate the model. After the spatial dependence of the residuals was discarded, GWR was applied considering the adaptativebandwidth kernel since it had the smaler AIC when compared with the fixed-bandwidth (Adaptative: 654.504; Fixed: 654.774). The GWR residuals were also analyzed for spatial autocorrelation. The adjusted $\mathrm{R}^{2}, \mathrm{AIC}$, and corrected Akaike information criterion (AICc) values obtained from the GWR were used to compare the OLS and GWR models.

\section{Results}

A total of 2220 HIV/AIDS cases were reported among young MSM in Pará between 2007 and 2018. However, only 2192 notifications were included in the study due to missing data. The average age of the young people notified was $23.6 \pm 2.12$ years, with most notifications in the age group of $20-24$ years $(n=995,45.39 \%)$. Most young people declared themselves as black $(n=1714,78.19 \%)$, with a high school education $(\mathrm{n}=875,39.92 \%)$, and as living in urban areas $(\mathrm{n}=2011,91.74 \%)$.

Temporal analysis revealed that the greatest variability in HIV/AIDS population-level diagnosis rates in young MSM from Pará occurred in January, May, June, August, and October (Fig. 2A). Concerning the historical series, the population-level diagnosis rate stabilized from 2007 to March 2013 and the trend increased thereafter (Fig. 2B). The best model to describe the variability of the data was STL + ARIMA $(0,1,2)$. Residual analysis showed a normal distribution (Kolmogorov-Smirnov $=0.04$, $p=0.65)$ and variance equality between the observation groups $(\mathrm{F}=0.88, p=0.70)$ and no autocorrelation (Ljung-Box $=31.69, p=0.06 ; \quad$ Box-Pierce $=1.66$, $p=0.99$ ).

The forecast of the behavior of the series from 2019 to 2022 revealed an increasing and oscillating trend with a $38.47 \%$ chance of error $(\mathrm{MAPE}=38.47, \mathrm{MAE}=0.13$, RMSE $=0.18$; Fig. 2C).

Figure 3 shows the spatial distribution of the crude HIV/AIDS population-level diagnosis rates for the quadrenniums, 2007-2010 (Fig. 3A), 2011-2014 (Fig. 3B), 2015-2018 (Fig. 3C), and for the 12 years of the study (Fig. 3D). The population-level diagnosis rate increased mainly in municipalities located in the southeast, southwest, and northeast of Pará.

Moran's global analysis did not reveal a spatial autocorrelation in the HIV/AIDS population-level diagnosis rates 2007-2010: $I=-0.06, p=0.26 ; 2011-2014$ : $I=0.06, p=0.74 ; 2015-2018: I=0, p=0.97 ; 2007-2018$ : $I=0, p=0.91$ ).

Figure $4 \mathrm{~A}$ shows the spatial risk analysis, in which three areas at risk of HIV/AIDS were revealed for young MSM. Belém had the highest risk $(\mathrm{RR}=6.71,95 \% \mathrm{CI}$ $6.16-7,30, p<0.001)$, followed by Santarém $(R R=2.76$, $95 \% \mathrm{IC}=2.4-3.18, p<0.001)$ and Castanhal $(\mathrm{RR}=2.1$, $95 \% \mathrm{IC}=1.72-2.56, p<0.001)$. The spatiotemporal analysis indicated Belém as the only risk zone from 2014 to 2018 ( $R R=10.72,95 \%$ CI 9.66-11.55, $p<0.001$, Fig. 4B).

For the spatial regression, data analysis using the OLS method revealed that "number of young men with formal employment," "average salary for the formally employed man," and "percentage of people aged 18 or over with elementary school level" are the best explanatory models (Table 1). Residual autocorrelation analysis did not reveal spatial dependence $(I=-0.01 ; p=0.97)$. The GWR method revealed a better fit in the regression analysis than the OLS (GWR: AICc $=659.48 ; R^{2}=0.752$, adjusted $\mathrm{R}^{2}=0.721 ; \quad$ OLS: $\mathrm{AIC}=727.65, \quad \mathrm{R}^{2}=0.514$, adjusted $\left.\mathrm{R}^{2}=0.503\right)$ and no spatial autocorrelation of residuals $(I=-0.08 ; p=0.12)$.

Figures $5 \mathrm{~A}, \mathrm{C}$ and $\mathrm{E}$ shows the spatial distribution of the independent variables and Figs. $5 \mathrm{~B}, \mathrm{D}$ and $\mathrm{F}$ shows 

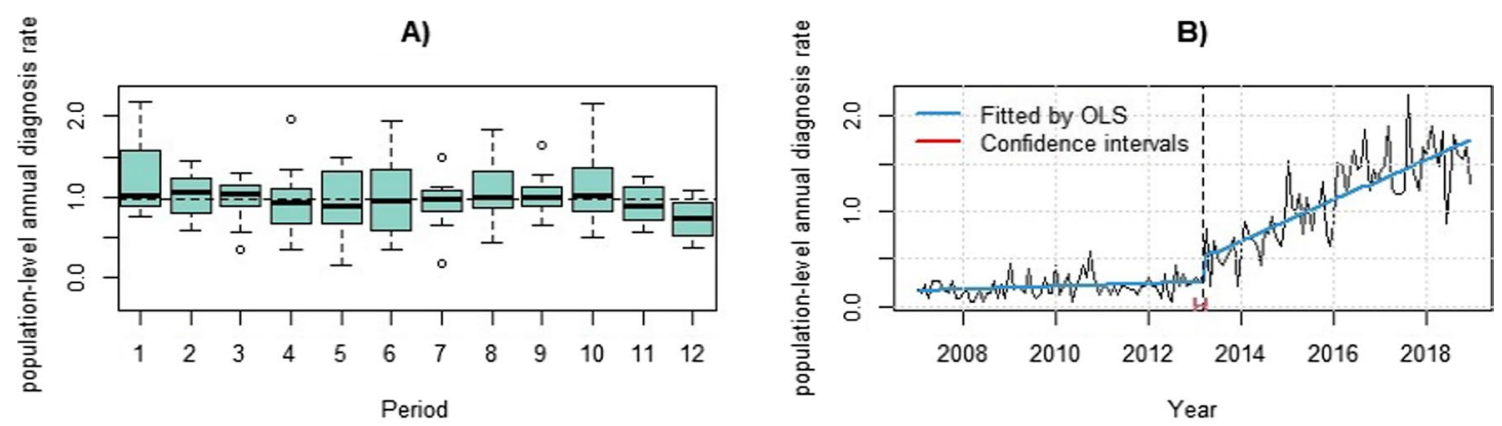

C)

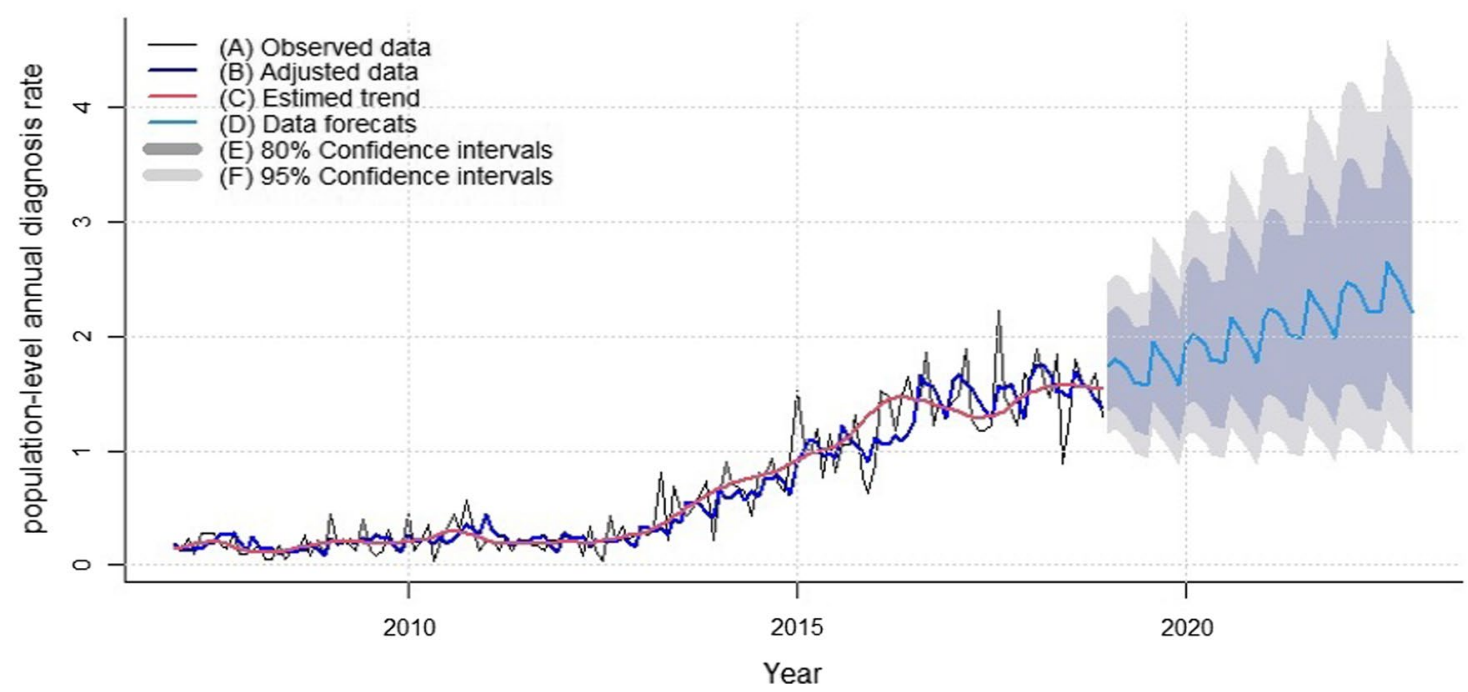

Fig. 2 Temporal variability and evolution of the HIV/AIDS population-level diagnosis rates among young MSM in Pará. A Monthly HIV/AIDS population-level diagnosis rates; B Temporal trend evolution of the HIV/AIDS population-level diagnosis rate between 2007 and 2018 ; C HIV/AIDS HIV/AIDS population-level diagnosis rate forecast from 2019 to 2022

the $\beta$ coefficients of the impact of independent variables on the HIV/AIDS population-level diagnosis rate among young MSM. In the southwest municipalities of Pará, the risk of an increase in the HIV/AIDS population-level diagnosis rates was directly proportional to the number of men with formal employment (Fig. 5B). Regarding the "average salary of men with formal jobs", the risk of an increase in the HIV/AIDS population-level diagnosis rates was negligible in the north, northeast and west of Pará, where most the municipalities had a small average salary for men with formal jobs (Fig. 5D). The same was noticed to "percentage of young people with elementary schooling" in municipalities in the center, midwest, and middle east of Pará (Fig. 5F).

\section{Discussion}

The results of this study showed that January, May, June, August, and October had the greatest variability in HIV/ AIDS population-level diagnosis rates in young MSM in Pará. From March 2013, the increasing trend of the HIV/AIDS population-level diagnosis diagnosis rate is expected to continue until 2022. From 2007 to 2018, the HIV epidemic among young MSM expanded mainly in the southeastern and southwestern municipalities of Pará. Belém, Santarém, and Castanhal had the highest spatial risk for HIV/AIDS. However, Belém was the only municipality to present a spatiotemporal risk between 2014 and 2018. The chance of an increase in the HIV/ AIDS diagnosis rate was directly associated with the number of men with formal employment in the southwest of Pará. However, it was negligible in the north, northeast, and west meridionals for the "average salary of men with formal jobs" and for "percentage of young people with elementary schooling" in municipalities in the center, midwest, and middle east of Pará.

The greater variability of HIV/AIDS population-level diagnosis diagnosis rates in January, May, June, August, and December can be explained by the festivities 
A

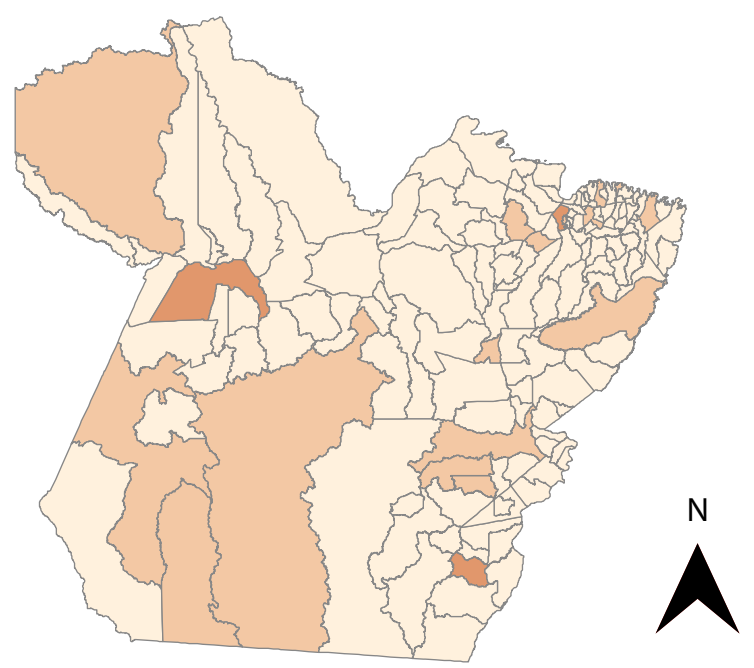

C
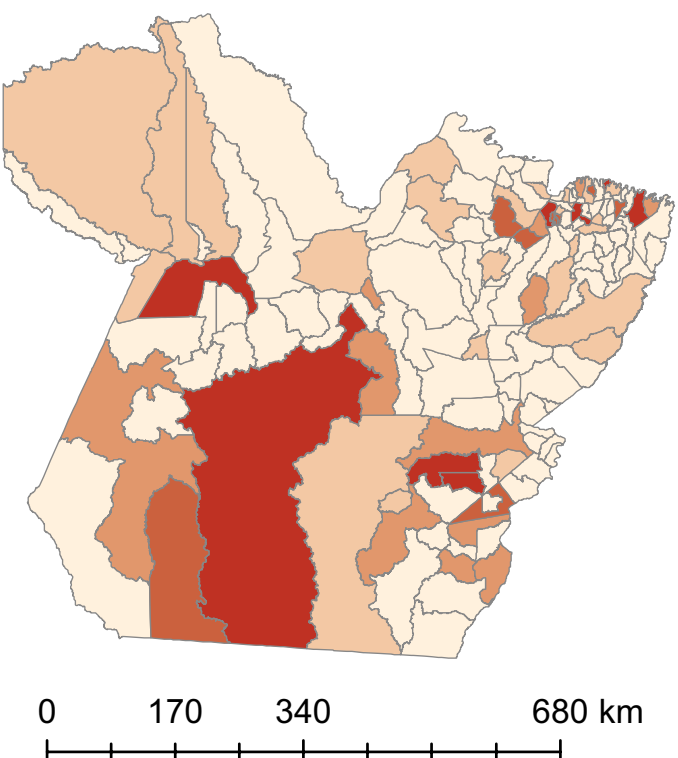

B

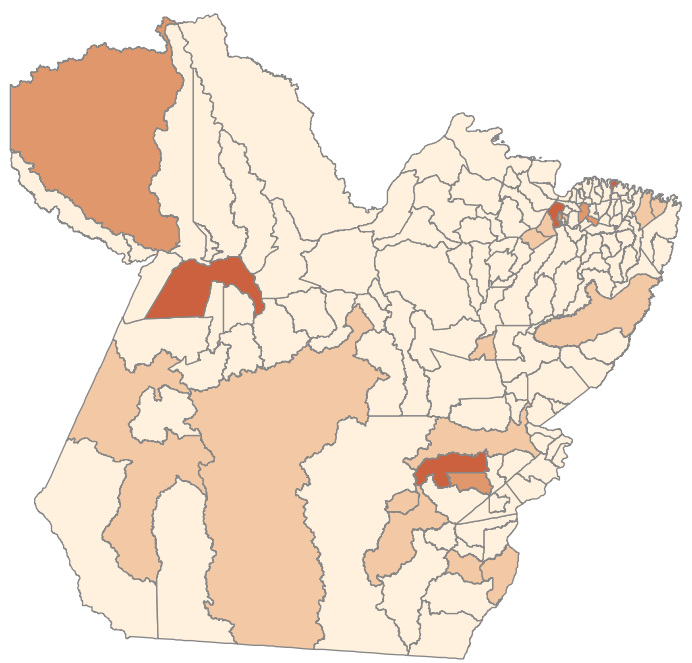

D

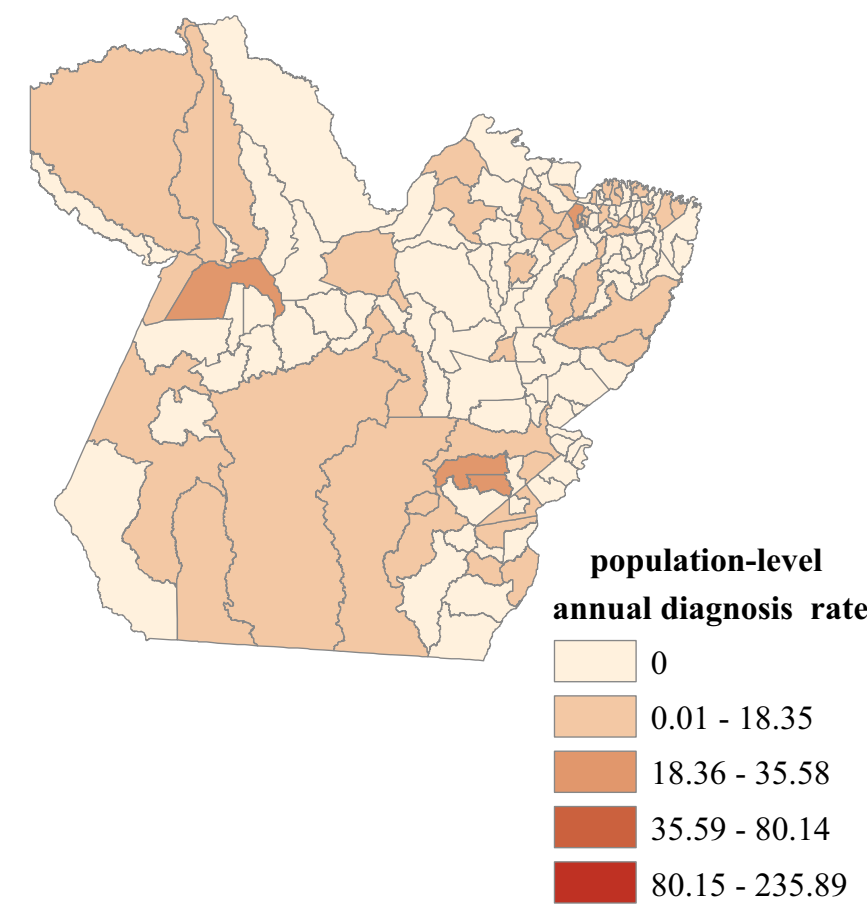

Fig. 3 Spatial distribution of the HIV/AIDS HIV/AIDS population-level diagnosis rates among young MSM in Pará. A 2007-2010, B 2011-2014, C 2015-2018, D 2007-2018

occurring in Pará. January and August follow the holiday season and the July holidays, respectively, where most of the people go to the beaches. In May and June occurs the Feast of Saint Jhon. In October, the catholic event "Círio de Nazaré" is celebrated in Belém, where a great number of tourists come to Belém with an estimative of over 2 million people in the main procession. This suggests a necessity of more preventive interventions against sexually transmissible infections in these months giving access to people to educative and preventive resources.

The trended up temporal behavior of the HIV/AIDS population-level diagnosis rates among Brazilian Amazonian young MSM from March 2013 to 2018 can be due to the expansion of the HIV tests promoted by the testing 


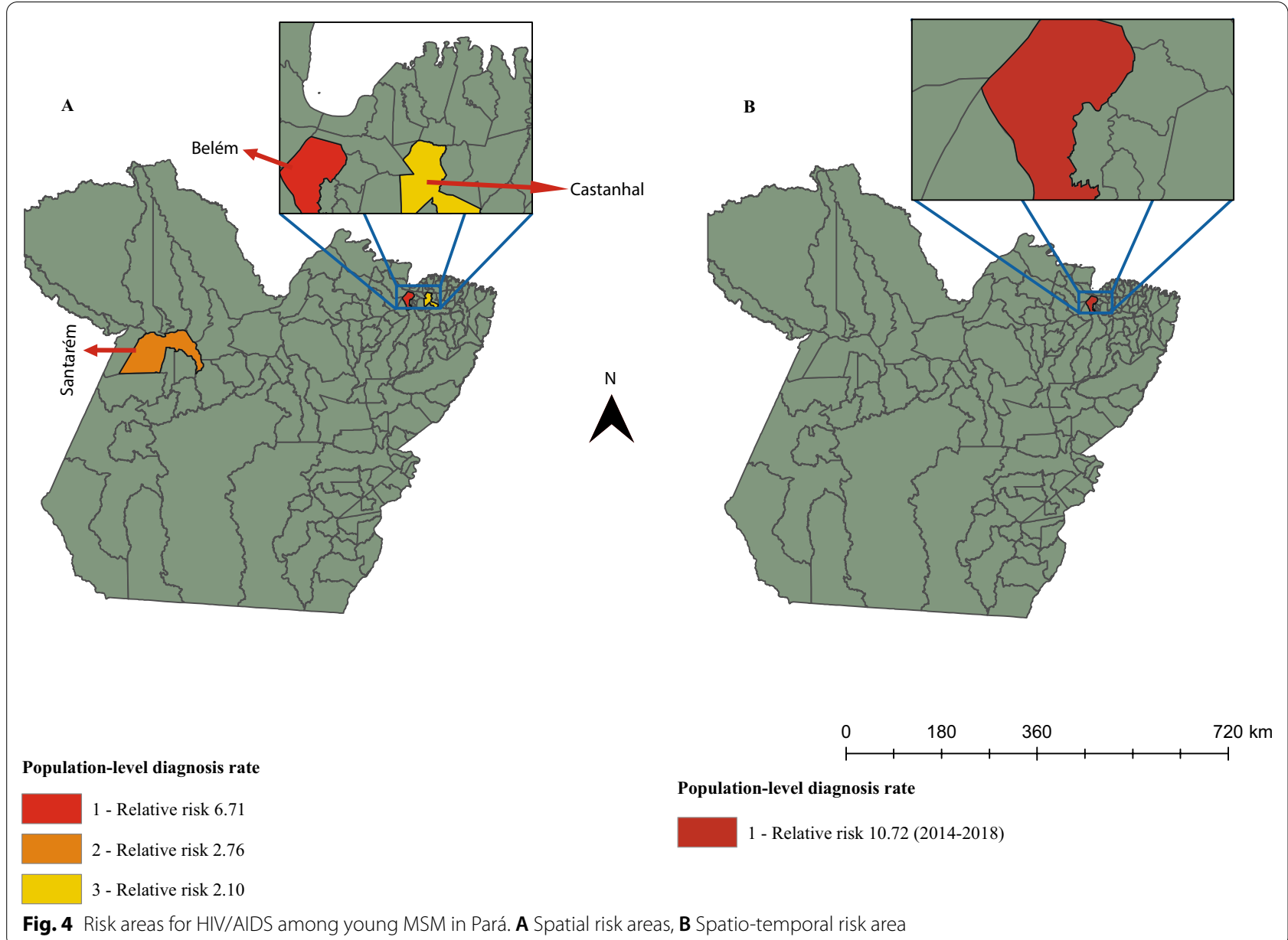

Table 1 OLS explicative model to the SDHs impact in HIV/AIDS detection rate in young MSM living in Pará, 2007-2018. Pará, Brazil

\begin{tabular}{|c|c|c|c|}
\hline Variável & Estimative & $\begin{array}{l}\text { Standard } \\
\text { deviation }\end{array}$ & p-valor \\
\hline Constant & -3.46 & 0.9 & $\mathrm{p}<0.001$ \\
\hline Number of men with formal jobs & 0 & 0 & $p<0.001$ \\
\hline Men's monthly wage average & 0.001 & 0.001 & 0.087 \\
\hline $\begin{array}{l}\% \text { of } 18 \text { years old people and over } \\
\text { with elementary schoolling }\end{array}$ & 0.92 & 0.025 & $p<0.001$ \\
\hline
\end{tabular}

$R^{2}, 0.51$ /adjusted $R^{2}: 0.50 ; A I C, 727.65$ decentralization in Brazil since 2011. Before 2011, all HIV tests were done only in the Testing and Counseling Centers in Brazil and nowadays the primary healthcare units are also responsible for the tests [21]. However, our results suggest that this decentralization impacted the HIV epidemic among young MSM in Pará only after 2013. From 2013 to 2018 the number of HIV tests received in Pará increased by 373.43\% (2013: 229.730 tests; 2018: 857.880 tests) [22].

In addition, the ascending temporal behavior of the HIV epidemic from March 2013 among young MSM

(See figure on next page.)

Fig. 5 Spatial mapping of the geographically variability of the HIV epidemic in Pará by geografically weighted regression (GWR) promoted by the social determinants of health (SDOH). Spatial distribution of the (A) Number of men with formal jobs, C Men's monthly wage average, $\mathbf{E} \%$ of 18 years old people and over with elementar schooling; Coefficients $\beta$ of (B) Number of men with formal jobs, D Men's monthly wage average, $\mathbf{F} \%$ of 18 years old people and over with elementar schooling 

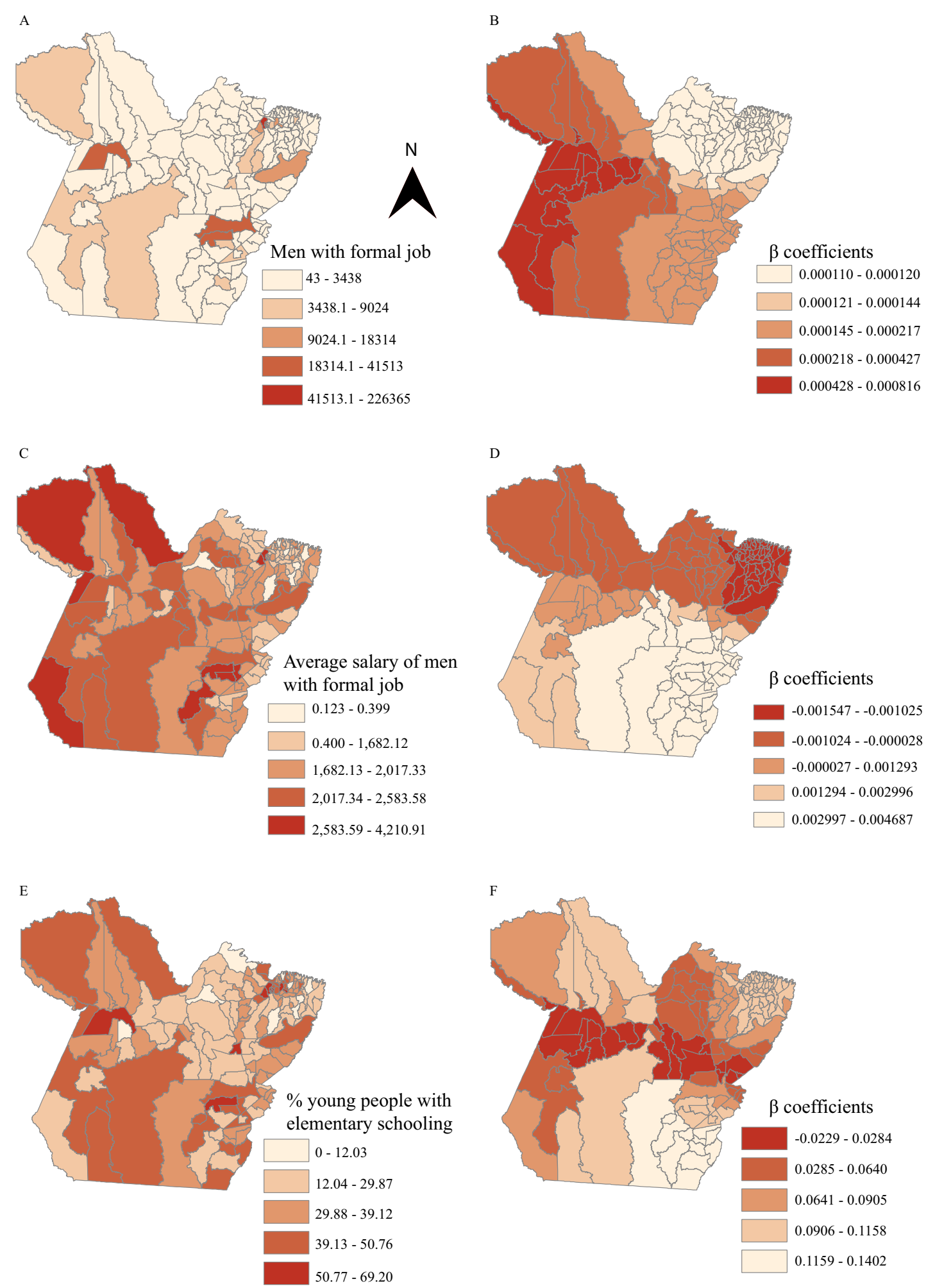

Fig. 5 (See legend on previous page.)

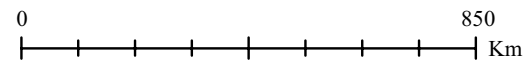


can be also due to the compulsory notification of HIV from 2014. Furthermore, in the same year, the Brazilian Health Ministry launched a policy entitled, "Treatment for All," to eliminate HIV infection by 2030 as proposed by the Joint United Nations Program on HIV/AIDS [23]. This policy expanded HIV test coverage and initiated antiretroviral therapy (ART) immediately after an HIV diagnosis regardless of $\mathrm{CD}_{4}{ }^{+} \mathrm{T}$-cells count. Although, the continuous increase in the HIV/AIDS population-level diagnosis rate until 2018 suggests a success of the expansion of HIV testing coverage in Pará, other locations that implemented the same policy the HIV populationlevel diagnosis rate decreased among MSM, as London (8.95\%) and Chengdu-China (29\%) $[24,25]$.

In addition, considering the larger territorial extension, all geographic and socioeconomic barriers to people access the healthcare places, such as densely forested areas, with access to urban areas only by boat, rainy climate, and poverty, Pará has minimal resources to fight HIV: in all the state there are only 33 ART-dispensing units, 7 specialized care services, and only 2 pre-exposure prophylaxis (PrEP)-dispensing units [26, 27]. Therefore, it is more than plausible the upward trend of the HIV/AIDS population-level diagnosis rates among MSM since 2013 and its forecasting maintenance until 2022. In central London, since 2015, the HIV population-level diagnosis rate among MSM decreased substantially after expanding and guaranteeing the access of MSM to HIV testing, treatment, and PrEP distribution [25]. In Miami, Florida US, although the HIV incidence rate has decreased among MSM, in the young Latin MSM group it still trending upward as this group have greater difficulty accessing prevention and HIV treatment centers [28].

In the Northern of Brazil, from 2018 to 2019, the number of HIV/AIDS cases among men increase 4.14\% (2018: 3190 cases; 2019: 3322 cases) [2]. Although we do not have Brazilian reported regional number of HIV/AIDS cases in men in 2020, the notification of cases in all country decreased 67.34\% (2019: 26,141 men cases; 2020: 8434 men cases). Although we do not have a reported regional number of HIV/AIDS cases in men in 2020, the notification of cases in all countries decreased $67.34 \%$ (2019: 26,141 men cases; 2020: 8,434 men cases). This decreasing could be due to underreporting cases since the health professionals were relocated to work with the COVID19 [2]. The population-level diagnosis rate trending up behavior from 2019 to 2022 brings an alert for the possible consequences of the reemergence of conservative politics in Brazil [29] and also of COVID-19 pandemic outbreak affecting the HIV combat policy.

The fact that only Belém, the capital of Pará, had a spatiotemporal risk for HIV between 2014 and 2018 suggests that the strategies to fight HIV have been more efficient in the capital than in other municipalities in the interior. Belém has a higher concentration of healthcare facilities with better access for the people to these services.

The spatial risk for HIV in Belém and Castanhal can be attributed to these cities having the first and fourth highest population densities in the state, respectively. This is in line with what was observed in India. The Indian districts with the highest HIV incidence rates were those with the highest population densities [30]. Santarém is an economic polo and a very touristic municipality in Pará. It attracts tourists from all over the world. Thus, sex tourism might have contributed to the HIV epidemic environment. In China, several HIV risk behaviors were observed among MSM who practiced sex tourism. These behaviors include sexual intercourse without condoms and sex with multiple partners [31]. In addition, another previous study in China showed the municipalities with high density populations and high economic growth had higher HIV population-level diagnosis rates among MSM [14].

The areas with high possibility for an increase in HIV among young MSM in Pará were those in the southern Pará having most of the municipalities with a high number of men with formal jobs, high avarage salary, and high $\%$ of men with elementary schoolling level. The souther Pará has a high DHI promoted by a rapid economic rise due to the expansion of the mining industries and hydroelectric constructions and has generated the greatest number of formal jobs in all the state. The young MSM with the best economic conditions can be more exposed to HIV for being allowed to travel abroad and more access to social media technologies, parties, and recreational drugs, for example. A previous study in Vietnam among MSM showed that traveling alone and having a university schooling level was associated with casual sex [32]. In addition, the use of sex-seeking applicatives and recreational drugs in parties is related to an increase in risk to HIV among MSM [33, 34].

Our results showed a greater risk of increasing in the HIV/AIDS population-level diagnosis rates in municipalities associated with the \% of young people with elementary schooling. In Pará, on average, the young people have 7.2 years of schooling [35]. To fight HIV among young people, in 2007 the Ministry of Health in Brazil launched the Health at School Program, having as one of the goals the promotion of the sexual health of young people and adolescent students. However, this study suggests a necessity to reinforce even more this policy. In Belém young high school students had a low level of knowledge about HIV and risk behaviors toward the virus, such as the infrequent use of condoms in sexual intercourse and multiple sexual partnerships [36]. 
The knowledge about HIV deficit can lead to a low HIV risk perception, contributing to the exposition of young MSM to the virus. For example, British MSM showing a low-risk perception of HIV presented more risk behaviors to the virus than MSM showing a high-risk perception [37]. In addition, a previous study comparing MSM behaviors in two different times, 2009 versus 2016, showed behavioral changes between the two groups. In 2016, the MSM had a higher schooling level and more condomless receptive and insertive sex with multiple partners, especially those using illicit drugs, with lower knowledge about HIV and counseling uptake [38].

Furthermore, HIV and anti-gay stigmas have also to be fought since they are barrier to MSM looking for HIV services [39]. Consistent with this, a previous study showed a lower acceptance of HIV testing among the MSM living in the Northern of Brazil when compared with other Brazilian regions because of their fear of having a positive result [8].

This study was limited by underreporting and the process of describing variables based on the health professional's judgment. We had to exclude 28 notifications due the missing the name of the municipalities, age, sex, or exposure group. This reinforces the necessity to capacity the health workers to a better quality of the notifications. Additionally, the database made available by the Brazilian Geography and Statistics Institute and Institute for Applied Economic Research was from 2010. Due to the blocking of the financial resource by the federal government, until the present date the new Brazilian census has not yet taken place. Furthermore, in the future census, it is essential to quantify MSM, lesbians, and other population extracts.

In addition, the forecasts up to 2022 did not consider the COVID-19 pandemic outbreak. However, the predictions are always obtained under the premise that there will be no disruptions in the future, and when they occur there are no mathematical models capable of predicting them. As a future study, it is necessary to compare these predictions of this current data with the impact of COVID-19 to see how it changed the prediction course.

\section{Conclusion}

In Brazil, young and MSM populations are considered a priority and a key population in the fight against HIV. However, it is concerning when considering the SDH and the scarcity of policies to combat HIV in Pará. Our study showed an upward trend in the HIV populationlevel diagnosis rate from 2019 to 2022 signalling an alert to health authorities to reinforce policies against HIV to break this preview. Furthermore, the spatial analysis showing the geographical variability of the HIV epidemic promoted by SHDs provides additional subsidies to focal and more efficient policies.

Public policy against HIV will not be successful if people do not have access to sexual health education, prevention, testing, or HIV treatment. Social equality and a guarantee of basic human rights to all citizens can prevent the 2022 forecasted increase in the HIV/AIDS population-level diagnosis rate.

\section{Abbreviations \\ AIC: Akaike information criterion; AICC: Corrected Akaike information criterion; AIDS: Acquired immunodeficiency syndrome; ARIMA: Autoregressive inte- grated moving average; $\mathrm{Cl}$ : Confidence interval; DHI: Development human index; GWR: Geographically weighted regression; HIV: Human Immunodefi- ciency Virus; LISA: Local indicator of spatial autocorrelation; MSM: Men who have sex with men; OLS: Ordinary least squares model; PrEP: Pre-exposure prophylaxis; SDOH: Social determinants of health; STLF: Locally weighted polynomial regression.}

\section{Acknowledgements}

Not applicable.

\section{Authors' contributions}

Concept and designed the study: ILS, AOP, TBR, GRONF, EPB; Collection of data: ILS, AOP, TBR, ALSF; Analysis and interpretation of data: ILS, AOP, GRONF, TBR, ALSF, DG, RAA, RARS, EPB; Revision of the paper: ILS, AOP, GRONF, TBR, ALSF, $D G, R A A, R A A R S, E P B$. All authors read and approved the final manuscript.

\section{Funding}

The design of the study, collection, analysis, analysis, and interpretation of the data were supported by the Coordenação de Aperfeicoamento de Pessoal de Nível Superior under grant number 88881.200527/2018-01, PROCAD-AM.

\section{Availability of data and materials}

The datasets analysed during the current study are not publicly available due restrictions apply to the availability of these data. All data in this study were used under license, and so are not publicly available.

\section{Declarations}

Ethics approval and consent to participate

The study was approved by the Research Ethics Committee of the Institute of Health Sciences, Federal University of Pará (CAAE 10821819.0.0000.0018) and written consented by the State Department of Public Health in Pará. All methods were performed in accordance with the Brazilian Heath Council, Resolution no 466 of December 12, 2012. Since we employed secondary data with no personal identifications the participant consent was unnecessary according to the Resolution $n^{\circ} 466$.

\section{Consent for publication}

Not applicable.

\section{Competing interests}

The authors declare no conflict of interest.

\footnotetext{
Author details

${ }^{1}$ Universidade Federal do Pará, Programa de Pós-Graduação em Enfermagem, Rua Augusto Correia, 01 - Setor saúde, GuamáBelém 66075-110, Pará, Brasil. ' ${ }^{2}$ Departamento de Vigilância Epidemiológica, Secretaria de Saúde Pública do Pará, Av. Doutor Freitas, 235 Sacramenta, 66123-050 Belém, Pará, Brasil. ${ }^{3}$ Maternal-Infant and Public Health Nursing Departament, University of São Paulo, College of Nursing at Ribeirão Preto, Avenida Dos Bandeirantes, 3900 - Campus Universitário, Monte Alegre, 14040-902 Ribeirão Preto, São Paulo, Brasil. ${ }^{4}$ Departamento de Matemática, Colégio Luís António Verney, Universidade de Évora, Rua Romão Ramalho,, 597000-671 Évora, Portugal. ${ }^{5}$ Departamento de Enfermagem, Centro de Ciências da Saúde, Universidade
} 
Federal do Rio Grande do Norte, Rua General Cordeiro de Faria, S/N. Petrópolis, 59012-570 Natal, Rio Grande do Norte, Brasil.

Received: 3 August 2021 Accepted: 15 February 2022

Published online: 24 February 2022

\section{References}

1. World Health Organization. HIV and youth. Internet. Geneva: WHO. 2020. https://www.who.int/maternal_child_adolescent/topics/adolescence/ hiv/en/. Accessed 20 June 2021.

2. Brasil. Ministério da Saúde. Secretária de Vigilância em Saúde. Boletim Epidemiológico: HIV/Aids 2021. Brasília: Ministério da Saúde. http:// www.aids.gov.br/pt-br/pub/2021/boletim-epidemiologico-hivaids-2021. Accessed 9 Jan 2022.

3. Brown MJ, Masho SW, Perera RA, Mezuk B, Cohen SA. Sex and sexual orientation disparities in adverse childhood experiences and early age at sexual debut in the United States: results from a nationally representative sample. Child Abuse Negl. 2015;46:89-102.

4. Nelson KM, Gamarel KE, Pantalone DW, Carey MP, Simoni JM. Sexual debut and HIV-related sexual risk-taking by birth cohort among men who have sex with men in the United States. AIDS Behav. 2016;20(10):2286-95.

5. Brasil. Senado Federal. Estatuto da Juventude: atos internacionais e normas correlatas. Internet. Brasília: Senado Federal. 2013. http://www2. senado.leg.br/bdsf/handle/id/509232. Accessed 20 June 2021.

6. Aagaard-Hansen J, Chaignat CL. Neglected tropical diseases: equity and social determinants in Equity, social determinants and public health programmes, Blass E, Kurup AS, editors. Geneva: World Health Organization. 2010. https://apps.who.int/iris/bitstream/handle/10665/44289/97892 41563970_eng.pdf? sequence $=1$ \&isAllowed=y. Accessed 20 June 2021.

7. Torres TS, Coelho LE, Konda KA, Vega-Ramirez EH, Elorreaga OA, Diaz-Sosa $D$, et al. Low socioeconomic status is associated with self-reported HIV positive status among young MSM in Brazil and Peru. BMC Infect Dis. 2021;21(1):1-9.

8. Torres TS, Marins LMS, Veloso VG, Grinsztejn B, Luz PM. How heterogeneous are MSM from Brazilian cities? An analysis of sexual behavior and perceived risk and a description of trends in awareness and willingness to use pre-exposure prophylaxis. BMC Infect Dis. 2019;19(1):1067.

9. da Silva AF, de Sousa JS, Araujo JA. Evidências sobre a pobreza multidimensional na região Norte do Brasil. Rev Adm Publica. 2017;51(2):219-39.

10. Neto FC. O geoprocessamento e saúde pública. Arq Ciênc Saúde. 2016;23(4):1-2.

11. Antunes JLF, Cardoso MRA. Uso da análise de séries temporais em estudos epidemiológicos. Epidemiol Serv Saúde. 2015;24(3):565-76.

12. Instituto Brasileiro de Geografia e Estatística. Cidades e Estados Pará. Internet. https://www.ibge.gov.br/cidades-e-estados/pa/.html. Accessed 10 April 2021.

13. Garnelo L, Lima JG, Rocha ESC, Herkrath FJ. Acesso e cobertura da Atenção Primária à Saúde para populações rurais e urbanas na região norte do Brasil. Saúde Debate. 2018:42(1 esp):81-99.

14. Qin Q, Guo W, Tang W, Mahapatra T, Wang L, Zhang N, et al. Spatial analysis of the human immunodeficiency virus epidemic among men who have sex with men in China, 2006-2015. Clin Infect Dis. 2017;64(7):956-63.

15. Brockwell PJ, Davis RA. Introduction to time series and forecasting. 2nd ed. New York: Spriger-Verlag; 2002.

16. Cleveland RB, Cleveland WS, MCRae JE, Terpenning I. STL: a seasonal-trend decomposition procedure based on loess. J Off Stat. 1990;6(1):3-73.

17. Zeileis A, Leisch F, Hornik K, Kleiber C. Strucchange: an R package for testing for structural change in linear regression models. J Stat Softw. 2002; 7(2):1-9.

18. Hyndman RJ, Athanasopoulos G. Forecasting: principles and practice; 3rd ed. Melbourne: OTexts; 2021.

19. Kulldorff M, Nagarwalla N. Spatial disease clusters: detection and inference. Stat Med. 1995;14(8):799-810.

20. Lin CH, Wen TH. Using Geographically Weighted Regression (GWR) to explore spatial varying relationships of immature mosquitoes and human densities with the incidence of dengue. Int J Environ Res Public Health. 2011;8(7):2798-815
21. Melo EA, Maksud I, Agostini R. Cuidado, HIV/Aids e atenção primária no Brasil: desafio para a atenção no Sistema Único de Saúde? Rev Panam Salud Pública. 2018:42(7):956-63.

22. Departamento de Doenças de Condições Crônicas e Infecções Sexualmente Transmissíveis. 2018 - distribuição de testes rápidos para HIV. http://www.aids.gov.br/pt-br/pub/2018/2018-distribuicao-de-testesrapidos-para-hiv. Accessed 27 Oct 2021.

23. Programa Conjunto Das Nações Unidas sobre HIV/AIDS. 90-90-90 Uma meta ambiciosa de tratamento para contribuir para o fim da epidemia de AIDS. Genebra: UNAIDS. 2015. https://unaids.org.br/wp-content/uploa ds/2015/11/2015_11_20_UNAIDS_TRATAMENTO_META_PT_v4_GB.pdf. Accessed 20 June 2021.

24. Wu C, Zhang B, Dai Z, Zheng Q, Duan Z, He Q, Zhu C. Impact of immediate initiation of antiretroviral therapy among men who have sex with men infected with HIV in Chengdu, southwest China: trends analysis, 2008-2018. BMC Public Health. 2021;21(1):689.

25. Nwokolo N, Hill A, McOwan A, Pozniak A. Rapidly declining HIV infection in MSM in central London. Lancet HIV. 2017;4(11):e482-3.

26. Departamento de Condições Crônicas e Infecções Sexualmente Transmissíveis. Serviços de saúde. Internet. Brasília: Ministério da Saúde. 2021. http://www.aids.gov.br/pt-br/acesso_a_informacao/servicos-de-saude? province=PA\&field_end_servicos_disponiveis_tid=All\&field_endereco_ tipo_tid=All. Acessed 20 June 2021.

27. Sistema de Controle Logístico de Medicamentos. Relação de UDMs Dispensando Medicamentos. Internet. SICLOM; 2021. http://azt.aids.gov. br/graficos/resumo.php?ufs=PA\&info_id=5. Accessed 10 April 2021

28. Kanamori M, Shrader CH, Stoler J, de Santana SA, Williams M. Geographic accessibility of HIV preventive services for young Latino men in Miami, Florida: a cross sectional study. J Assoc Nurses AIDS Care. 2021;32(1):68-78.

29. Agostini R, Rocha F, Melo E, Maksud I. A resposta brasileira à epidemia de HIV/AIDS em tempos de crise. Cien Saude Colet. 2019;24(12):4599-604.

30. Joshi RK, Mehendale SM. Determinants of consistently high HIV prevalence in Indian Districts: a multi-level analysis. PLoS One. 2019;14(5):e0216321.

31. Mao J, Tang W, Liu C, Wong NZ, Tang S, Wei C, Tucker JD. Sex tourism among Chinese men who have sex with men: a cross-sectional observational study. BMC Public Health. 2018:8:306.

32. Nguyen $H$, Nguyen $H Q$, Colby DJ. HIV knowledge and risks among Vietnamese men who have sex with men travelling abroad. Int I STD AIDS. 2014;25(9):643-9.

33. Martinez EZ, Morigi TZ, Galdino G, McFarland W, Zucoloto ML. Sex-seeking mobile application use and risk behavior among men who have sex with men in Brazil. Int J STD AIDS. 2020;31(12):1161-8.

34. Cheung DH, Lim SH, Guadamuz TE, Koe S, Wei C. The potential role of circuit parties in the spread of HIV among men who have sex with men in asia: a call for targeted prevention. Arch Sex Behav. 2015;44(2):389-97.

35. Secretaria Estadual de Educação. Documento Base do Plano Estadual de Educação. http://www.cee.pa.gov.br/sites/default/files/PLANO\%20EST ADUAL\%20DE\%20EDUCAÇÃO06052015_0.pdf. Accessed 27 Oct 2021.

36. de Lima MS, Raniere JC, Paes CJO, Gonçalves LHT, Cunha CLF, Ferreira GRON, et al. The association between knowledge about HIV and risk factors in young Amazon people. Rev Bras Enferm. 2020;73(5):e26060.

37. Clifton S, Nardone A, Field N, Mercer CH, Tanton C, Macdowall W, et al. HIV testing, risk perception, and behaviour in the British population. AIDS. 2016;30(6):943-52.

38. Guimarães MDC, Kendall C, Magno L, Rocha GM, Knauth DR, Leal AF, et al. Comparing HIV risk-related behaviors between 2 RDS national samples of MSM in Brazil, 2009 and 2016. Medicine. 2018;97(1S):S62-8.

39. Gyamerah AO, Taylor KD, Atuahene K, Anarfi JK, Fletcher M, Raymond $H F$, et al. Stigma, discrimination, violence, and HIV testing among men who have sex with men in four major cities in Ghana. AIDS Care. 2020;32(8):1036-44.

\section{Publisher's Note}

Springer Nature remains neutral with regard to jurisdictional claims in published maps and institutional affiliations. 